This item was submitted to Loughborough's Research Repository by the author.

Items in Figshare are protected by copyright, with all rights reserved, unless otherwise indicated.

\title{
Sixth-harmonic back-EMF based sensorless control for switched-flux permanent magnet machine
}

PLEASE CITE THE PUBLISHED VERSION

http://dx.doi.org/10.1109/VPPC.2016.7791776

PUBLISHER

(C) IEEE

VERSION

VoR (Version of Record)

LICENCE

CC BY-NC-ND 4.0

\section{REPOSITORY RECORD}

Lin, Tzu-Chi, J.M. Liu, and Zi-Qiang Zhu. 2019. "Sixth-harmonic Back-emf Based Sensorless Control for Switched-flux Permanent Magnet Machine”. figshare. https://hdl.handle.net/2134/24443. 


\title{
Sixth-Harmonic Back-EMF Based Sensorless Control for Switched-Flux Permanent Magnet Machines
}

\author{
T.C. Lin, J.M. Liu and Z. Q. Zhu \\ Department of Electronic and Electrical Engineering, \\ University of Sheffield, UK
}

\begin{abstract}
In switched-flux permanent magnet (SFPM) machines, the 6th-harmonic back electromotive force (EMF) is dominant, whilst the 3rd-harmonic back-EMF is much smaller. This paper proposes several new position estimation methods for sensorless control based on the 6th-harmonic back-EMF. Firstly, by detecting the zero-crossings of the 6th-harmonic back-EMF with/without eliminating the influence of the 3rd-harmonic back EMF, the related rotor positions can be determined precisely at these zero-crossings. However, since the intermediate rotor positions need to be determined by linear interpretation between two zero-crossings, it only exhibits excellent performance under steady state. Furthermore, the continuous rotor position can be estimated from the proposed new observer by utilizing the combined signals of 6th-harmonic back-EMF and flux-linkage, together with a synchronous reference frame filter (SRFF) and harmonic elimination. Experimental validation show that (a) by eliminating the 3rd-harmonic back-EMF effect, the accuracy of the proposed 6th-harmonic back-EMF zero-crossings detection method can be improved, (b) SRFF is effective to minimize the influence of non-constant amplitudes of the 6th-harmonic backEMF and flux-linkage, (c) the comparison between the fundamental, the 3rd-harmonic back-EMF and the proposed method are presented in order to highlight the effectiveness of proposed control strategy under different operating conditions.
\end{abstract}

Keywords - harmonic back-EMF, high-resolution rotor position estimator, permanent magnet machine, SFPM machine, sensorless control, switched flux.

\section{INTRODUCTION}

Permanent magnet (PM) machines have been widely employed in many industrial applications due to high torque density, power density, and efficiency. In order to achieve high control performance and minimize the current harmonics and torque ripples, a high resolution vector controlled method which requires accurate rotor position information has to be implemented. Hence, many high performance sensorlessbased control techniques have been considered, including the methods utilizing the back-EMF or the machine saliency to detect the rotor position information [1]-[5]. Back-EMF based sensorless control techniques can be categorised as integration of back-EMF which is PM excitation flux-linkage [6]-[8], zero-crossings of fundamental back-EMF [2][9], and harmonic back-EMF i.e. third order of harmonic components [10]-[14].

However, for some PM synchronous machines, the 3rdharmonic back-EMF does not exist or very small. Hence, the proposed method in this paper for extracting the harmonic back-EMF is specifically developed for some particular machines such as SFPM machines in which the 3rd- and 6thharmonic back-EMFs exist. By comparison, the 6th-harmonic back-EMF in the prototype $12 / 10$ stator/rotor pole SFPM machine is dominant and can be used for the sensorless control operation. Besides, it has similar principle as the method based on the 3rd-harmonic back-EMF [11][14].

In terms of the rotor position estimation, the integration of 6th-harmonic back-EMF, i.e. the 6th-harmonic flux-linkage, is utilized. By detecting the zero-crossings of the 6th-harmonic flux-linkage with/without eliminating the influence of the 3rdharmonic back-EMF, the rotor position can be accurately estimated. However, the performance at steady state can only be guaranteed, and the degradation occurs at dynamic state due to the sharp change of estimated rotor position. In order to enhance the accuracy of rotor position estimation, the continuous rotor position can be obtained from the proposed new observer by utilizing the combined signals of 6th-hrmonic back-EMF and flux-linkage as the reference input signals, together with a synchronous reference frame filter (SRFF) and harmonic compensation. The experimental comparison amongst the fundamental, the 3rd-harmonic back-EMF and the proposed method will be given for highlighting the effectiveness of proposed control strategy. Furthermore, the experiments will be carried out under different operating conditions, i.e. steady and dynamic states with/without compensation.

\section{CONFIGURATION OF SFPM MACHINE AND BACK-EMF ANALYSIS}

For the prototype SFPM machine under investigation, it is comprised of four series-connected winding coils for each phase, i.e. coils A1-A4 for phase A and the same for phase B and $\mathrm{C}$ as shown in Fig.1. The back-EMF waveforms induced in the different winding configurations are analyzed in order to investigate the harmonic components in the back-EMFs.

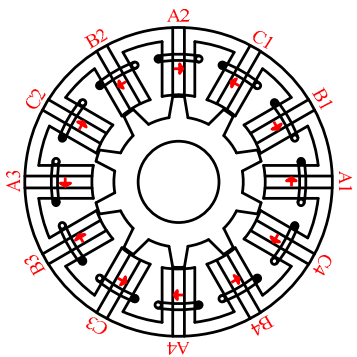

Fig. 1. Topology of SFPM machine. 
The back-EMF waveforms for each of the two pairs of diametrically opposite coil combination, namely A1A3 and A2A4 are shown in Fig. 2 (a), together with the resultant backEMF waveform when the two pairs of coil combination are connected in series. It clearly shows that the back-EMF waveforms for the two pairs of coil combination A1A3 and A2A4 are asymmetric and non-sinusoidal. Both back-EMF waveforms are rich of the harmonics, i.e. 2nd, 4th and 6th harmonics, which also include odd harmonics with small amplitudes according to the Discrete Fourier Transform (DFT) analysis shown in Fig. 2 (b). However, when the two pairs of perpendicularly disposed coil combination A1A3 and A2A4 are connected in series, the harmonics is cancelled. Therefore, the resultant phase back-EMF is essentially sinusoidal, as can be seen in Fig. 2 (a).

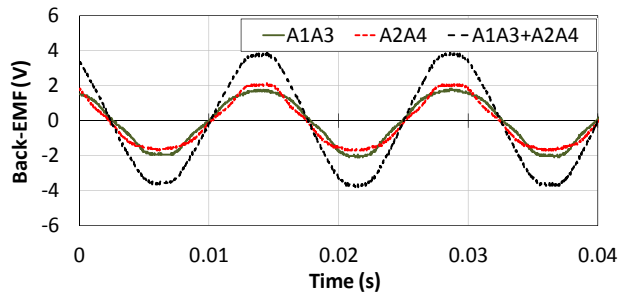

(a) Measured back-EMFs

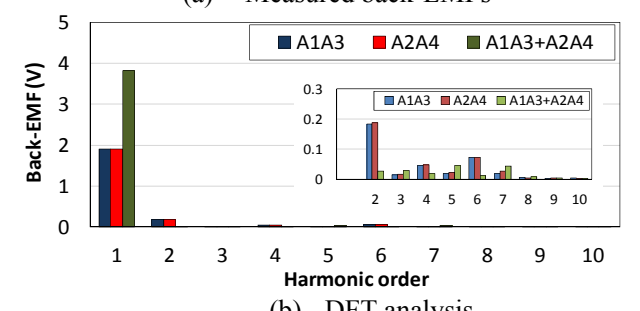

(b) DFT analysis

Fig. 2. Phase A back-EMFs based on different winding configurations.

\section{DETECTION OF SIXTH HARMONIC BACK-EMF AND THIRD HARMONIC CANCELLATION}

Considering the machine windings are Y-connected, the fundamental phase back-EMF may include some un-known orders of harmonic, which can be easily sensed. Then, the Yconnected resistance network is required [11]. The neutral point " $n$ " of Y-connected stator windings and the central point " $s 1$ " and " $s 2$ " of Y-connected resistance networks in Fig. 3 are employed to measure the harmonic back-EMFs.

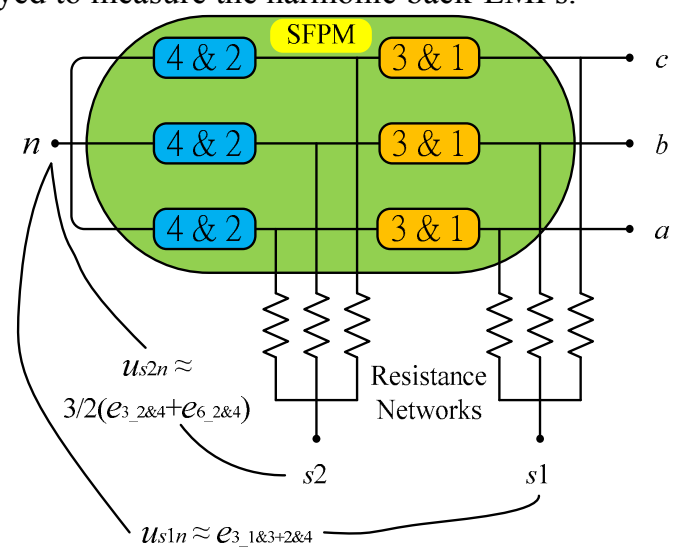

Fig. 3. Detection of harmonic back-EMFs.
Based on the Fourier analysis, the sum of three-phase voltage equation can be derived as

$$
\begin{aligned}
u_{a n}+u_{b n}+u_{c n} & =e_{a_{-} 1 \& 3+2 \& 4}+e_{b_{-} 1 \& 3+2 \& 4}+e_{c_{-} 1 \& 3+2 \& 4} \\
& =3 \times\left(e_{3 \_1 \& 3+2 \& 4}+e_{6_{-} 1 \& 3+2 \& 4}+e_{9 \_1 \& 3+2 \& 4}+\cdots\right)(1) \\
& \approx 3 \times\left(e_{3 \_1 \& 3+2 \& 4}\right)
\end{aligned}
$$

where $u_{a n}, u_{b n}$ and $u_{c n}$ are the three-phase voltage. $e_{a \_1 \& 3+2 \& 4}$, $e_{b_{-} 1 \& 3+2 \& 4}$ and $e_{c_{-} 1 \& 3+2 \& 4}$ are the phase A, B and C back-EMF. Then, the average of the sum of three phase back-EMFs can be expressed as

$$
u_{s 1 n}=\left(u_{a n}+u_{b n}+u_{c n}\right) / 3
$$

where $u_{s 1 n}$ is the harmonic back-EMF irrespective of the operational mode of the PMSM.

According to (1) and (2), a triplen harmonics as described in (3) is measured between the central point " $s 1$ " of the first resistance network and the machine neutral point " $n$ ", from which the harmonic back-EMF of $u_{s 1 n}$ can be obtained as

$$
\begin{aligned}
u_{s 1 n} & =\left(e_{3 \_1 \& 3+2 \& 4}+e_{6 \_1 \& 3+2 \& 4}+e_{9 \_1 \& 3+2 \& 4}+\cdots\right) \\
& \approx e_{3 \_1 \& 3+2 \& 4}
\end{aligned}
$$

Similarly, the harmonic back-EMF of $u_{s 2 n}$ is measured between the machine winding neutral point " $n$ " and the central point " $s$ " of the second resistance network, which can be derived as

$$
\begin{aligned}
u_{s 2 n} & =\left(u_{a n_{-} 2 \& 4}+u_{b n_{-} 2 \& 4}+u_{c n_{-} 2 \& 4}\right) / 3 \\
& =\left(e_{a_{-} 2 \& 4}+e_{b_{-} 2 \& 4}+e_{c_{-} 2 \& 4}\right) / 3 \\
& =e_{3 \_2 \& 4}+e_{6 \_2 \& 4}+e_{9 \_2 \& 4}+\cdots \approx e_{3 \_2 \& 4}+e_{6 \_2 \& 4} \\
& \approx \frac{1}{2} \times\left(e_{3 \_1 \& 3+2 \& 4}+e_{6 \_1 \& 3+2 \& 4}\right)
\end{aligned}
$$

where $u_{s 2 n}$ represents the harmonic back-EMF measuring from the winding coil 2 connecting with winding coil $4 . u_{a n \_2 \& 4}$, $u_{b n_{-} 2 \& 4}$ and $u_{c n \_2 \& 4}$ are the phase voltage of the winding coil 2 connecting with winding coil 4. $e_{a_{-} 2 \& 4}, e_{b_{-} 2 \& 4}$ and $e_{c_{2}} 2 \& 4$ present the back-EMF of the winding coil 2 connecting with winding coil 4.

In Fig. 4, the harmonic back-EMF waveforms are measured. More specifically, the amplitude of $u_{s 2 n}$ is obviously bigger than that of $u_{s 1 n}$. It shows that the $6^{\text {th }}$ harmonic component in $u_{s 2 n}$ is dominant and can utilize for the rotor position estimation. However, it is also found that $u_{s 2 n}$ includes a large $3^{\text {rd }}$ harmonic component which may affect the control operation, and needs to be further eliminated.

Additionally, Figs. 4 (a) show that the amplitudes of harmonic back-EMF of $u_{s 1 n}$ and $u_{s 2 n}$ are relatively small, and may include some low frequency noise or DC offset. Hence, they can be amplified to a significant level as shown in Fig. 4 (b) by a Texas Instrument TL074 operational amplifier in order to increase the control stability.

As mentioned, the large $3^{\text {rd }}$ harmonic component is included in $u_{s 2 n}$. Thus, the 3rd-harmonic component measured from $u_{s 1 n}$ can be used to reduce the influence of $3^{\text {rd }}$ harmonic on $u_{s 2 n}$ as its amplitude is twice, which can be derived as 


$$
\begin{aligned}
u_{s 1 n} & =e_{3 \_1 \& 3+2 \& 4} \approx 2 \times e_{3 \_2 \& 4} \\
u_{s 2 n} & =\frac{1}{2} \times\left(e_{3 \_1 \& 3+2 \& 4}+e_{6 \_1 \& 3+2 \& 4}\right) \\
& =e_{3 \_2 \& 4}+e_{6 \_2 \& 4}
\end{aligned}
$$

In order to minimize the influence of $3^{\text {rd }}$ harmonic on $u_{s 2 n}$, a simple method is proposed, and can be re-expressed as

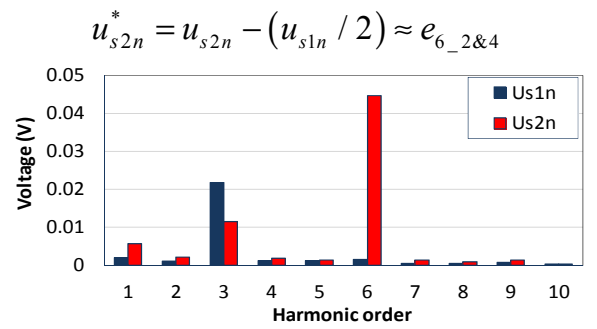

(a) DFT analysis - Original

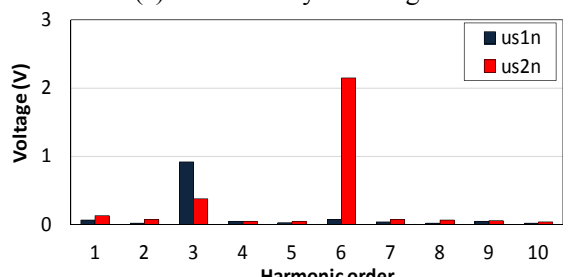

(b) DFT analysis - Amplified

Fig. 4. Measured harmonic back-EMFs analysis.

In Fig. 5, the $3^{\text {rd }}$ harmonic component effect on $u_{s 2 n}$ is analyzed, and has significantly been reduced in $u_{s} 2 n$. Moreover, it can be anticipated that if the influence of the $3^{\text {rd }}$ harmonic on $u_{s 2 n}$ can completely be eliminated by the proposed method; the more accurate rotor position estimation will be achieved.

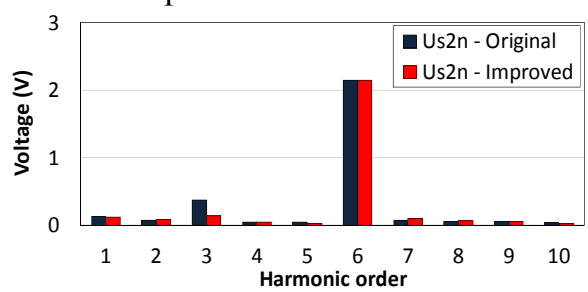

Fig. 5. Influence of third harmonic on back-EMF of $u_{s 2 n}$.

\section{EXISTING BACK-EMFs BASED Rotor Position ESTIMATIONS}

\section{A. Rotor Position Estimation Based on Fundamental Back- $E M F$}

The most commonly used method for sensorless control in medium and high speed ranges is the fundamental back-EMF based observer [6][7]. The algorithm of the fundamental backEMF technique according to [15], can be expressed as

$$
\begin{gathered}
u_{\alpha}=R_{s} i_{\alpha}+\frac{d}{d t}\left(L_{s} i_{\alpha}+\psi_{p m} \cdot \cos \theta_{r}\right) \\
u_{\beta}=R_{s} i_{\beta}+\frac{d}{d t}\left(L_{s} i_{\beta}+\psi_{p m} \cdot \sin \theta_{r}\right) \\
\psi_{s_{-} \alpha \beta}=\int\left(u_{\alpha \beta}+\psi_{p m} \times i_{\alpha \beta}\right) \cdot d t \\
\theta_{r}^{e}=\tan ^{-1} \frac{\psi_{s_{-} \beta}}{\psi_{s_{-} \alpha}}
\end{gathered}
$$

where $\psi_{p m}, u$ and $i$ are the PM flux linkage, terminal voltage and measured current, respectively. $R_{s}$ is the stator resistance and $L_{s}$ is the winding inductance. $\theta_{r}$ is referred as the electrical rotor position. However, the only issue for the fundamental method is the sensitivity of parameters which need to be accurate otherwise the accuracy of the rotor position estimation will be degraded.

\section{B. Rotor Position Estimation Based on Third-Harmonic Back-EMF}

Another back-EMF based method is to utilize the harmonic back-EMF for the rotor position estimation, such as the 3rdharmonic back-EMF [11][12][14].

According to [11][14], the initial rotor position $\theta_{0}$ of each half-cycle between two zero-crossings could be known. Then, the estimated rotor position can be calculated by simple integration as

$$
\theta_{r}^{e}=\theta_{0}+\int_{0}^{t} \omega_{r} d t=\theta_{0}+\int_{0}^{t} \frac{\pi / 3}{t_{d}} d t
$$

where $\omega_{r}$ in (12) is the average machine speed which can be calculated from the time cycle of zero-crossings, whilst $\Delta t_{c}$ is the time interval of position estimation. However, for this method, the estimated rotor position will only be accurate under steady-state and inaccurate during dynamic transient.

\section{Proposed Sixth Harmonic BACK-EMF BASED ROTOR POSITION ESTIMATIONS}

\section{A. Rotor Position Estimation Based on Integration and Zero Crossings Detection}

In Fig. 6, the initial rotor position $\theta_{0}$ is calculated from the integration of $u_{s 2 n}^{*}$ which is the 6th-harmonic flux-linkage of $\psi_{s n}$ comparing with the electrical rotor position $\theta_{r}$.

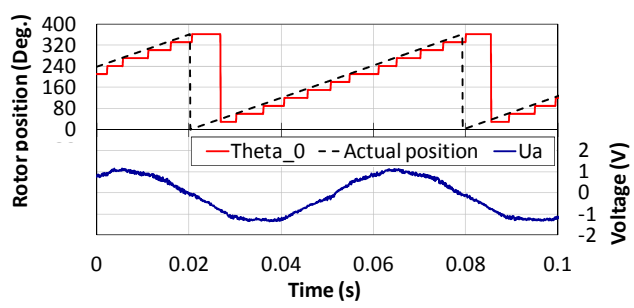

Fig. 6. Rotor positions with phase A terminal voltage, $100 \mathrm{r} / \mathrm{min}$.

The terminal voltage $u_{a}$ is required for detecting the first related rotor position of zero-crossings of $\psi_{s n}$ which is $\pi / 12$. When the first related rotor position is obtained, the following discrete positions can also be located, which are $\pi / 4,5 \pi / 12$, $7 \pi / 12,3 \pi / 4,11 \pi / 12,13 \pi / 12,5 \pi / 4,17 \pi / 12,19 \pi / 12,7 \pi / 4$ and $23 \pi / 12$. The integration and zero-crossings based rotor position estimator is described in Fig. 7.

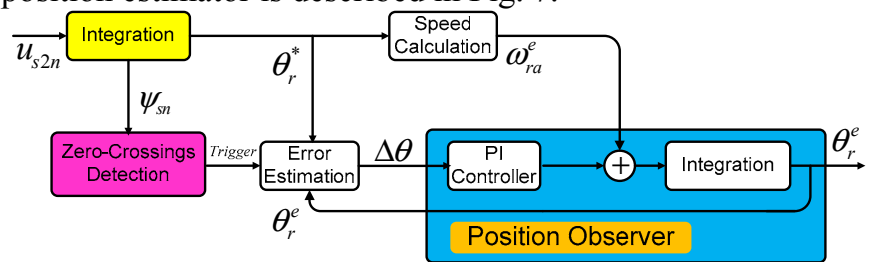

Fig. 7. Integration and zero-crossings based rotor position estimations. 
Since the zero-crossings of the 6th-harmonic flux-linkage are related to the rotor positions, each cycle between two zerocrossings can be located in order to detect the initial rotor position $\theta_{0}$. Then, the estimated rotor position $\theta_{r}^{e}$ can be calculated by integration [11][14] as

$$
\theta_{r}^{e}=\theta_{0}+\int_{0}^{t} \omega_{r}^{e} d t
$$

where $\omega_{r}^{e}$ is the estimated speed that calculates from the time duration between the zero-crossings of $\psi_{s n}$ and current, and usually the average speed between the last two zero-crossings of $\psi_{s n}$, i.e.

$$
\omega_{r}^{e}=\frac{\pi / 6}{t_{d}}
$$

where $t_{d}$ is referred as the time interval of the previous half cycle between two zero-crossings of $\psi_{s n}$

The rotor position estimation at steady-state can exhibit high accuracy estimation since the speed is constant. However, during dynamic transient state, the sharp change is happened and will deteriorate the performance due to the inaccurate speed variation, e.g. causing current distortion and torque pulsating. Hence, the phase-locked loop (PLL) based position observer is employed to avoid this issue, but the operation is still limited due to the influence of non-constant amplitude.

\section{B. Proposed Rotor Position Estimation Based on the Sixth- Harmonic Back-EMF}

As mentioned before, if the $3^{\text {rd }}$ harmonic component in $u_{s 2 n}$ is completely cancelled, the calculated $u_{s 2 n}^{*}$ will mainly be the 6th-harmonic back-EMF. Hence, its integration, i.e. the 6th-harmonic flux-linkage $\psi_{s n}$ will be a continuous sinusoidal signal with constant amplitude, and are used as the reference input signals for the proposed observer. A compensation scheme i.e. SRFF [4] as described in Fig. 8 together with a 3rd-harmonic compensation and novel rotor position estimation shown in Fig. 9 are proposed to reduce the error in the rotor position estimation.

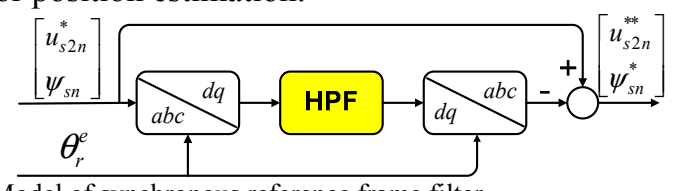

Fig. 8. Model of synchronous reference frame filter.

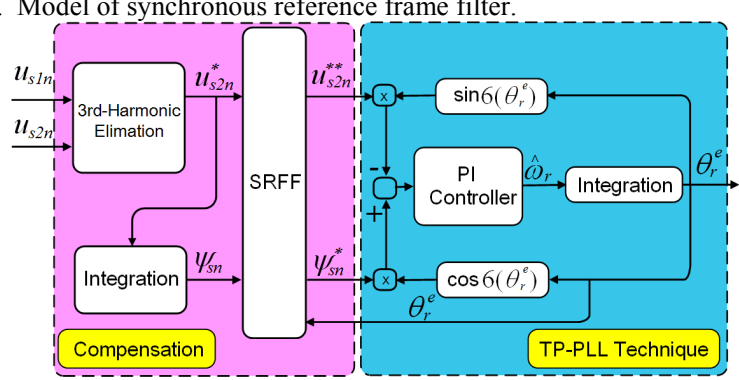

Fig. 9. Proposed observer with non-constant compensation scheme.

In SRFF, the high-pass filter (HPF) is chosen to eliminate the harmonics. It is basically based on the two signals. One is (7) which can be rewritten as

$$
u_{s 2 n}^{*}=K_{a p} \sin \left(\omega_{r} t+\varphi_{u}\right)+e_{6 \_2 \& 4}=K_{a p} \sin \left(6 \times \theta_{r}\right)
$$

where $K_{a p}, \omega_{r}$ and $\varphi_{n}$ are the amplitude, angular speed and initial phase angle of the 6th-harmonic back-EMF, and its integration $\psi_{s n}$ which can be expressed as

$$
\psi_{s n}=-A_{a p} \cos \left(6 \times \theta_{r}\right)
$$

where $A_{a p}$ is the amplitude of $\psi_{s n}$. The effectiveness of the non-constant compensation scheme is validated as shown in Fig. 10. Clearly, the 6th-harmonic flux-linkage and the unified 6th-harmonic back-EMF with non-constant amplitude have significantly been improved.

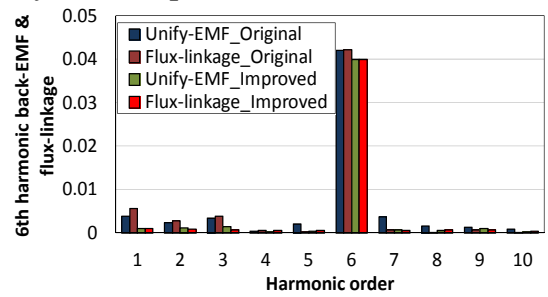

Fig. 10. Measured sixth-harmonic flux-linkage and unified sixth-harmonic back-EMF with proposed compensation scheme.

After compensation, the 6th-harmonic flux-linkage become a continuous signal with constant amplitude, which can be represented as

$$
\psi_{s n}^{*}=-A_{p} \cos \left(6 \times \theta_{r}\right)
$$

where $A_{p}$ is the amplitude of $\psi_{s n}^{*}$. $A_{p}$ varies with different temperature of PM. It should be detected in every cycle in order to avoid the amplitude changing. Besides, the assistant signal of $u_{s 2 n}^{*}$, its amplitude is related to rotor position and varying with the rotor speed $\omega_{r}^{e}$, can be unified to $A_{p}$, which is rewritten as

$$
u_{s 2 n}^{* *}=\frac{K_{p}}{\omega_{r}^{e}} E_{6} \sin \left(6 \times \theta_{r}\right)=A_{p} \sin \left(6 \times \theta_{r}\right)
$$

where $\omega_{r}^{e}$ is the estimated speed response and $K_{p}$ is the unifyvalue of the 6th-harmonic back-EMF. In order to obtain the continuous rotor position from (17) and (18), the PLL observer is employed which was first published in [16]. The close-loop transfer function between the actual and estimated rotor position information can be expressed as

$$
\frac{\theta_{r}^{e}}{\theta_{r}}=\frac{6 A_{p} k_{p} \cdot s+6 A_{p} k_{i}}{s^{2}+6 A_{p} k_{p} \cdot s+6 A_{p} k_{i}}
$$

Equation (19) represents as a simple standard second-order control system. The values of $k_{p}$ and $k_{i}$ of PI controller can easily be determined and on-line adjusted. By applying the PLL observer together with the aid of SRFF, the high accuracy of continuous rotor position estimation can be achieved at both steady and dynamic states.

\section{EXPERIMENTAL RESULTS}

In order to demonstrate the effectiveness of the 6thharmonic back-EMF based sensorless control operation, both steady and dynamic performances have been carried out on the prototype machine as shown in Fig.11, whose parameters are listed in Table I. 


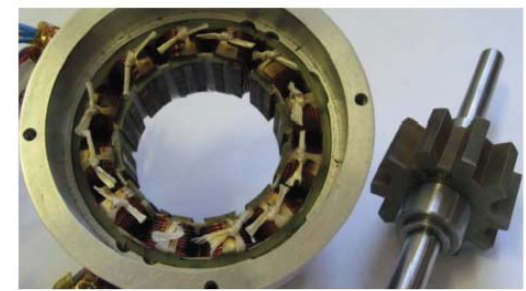

Fig. 11. 12/10 stator/rotor pole SFPM prototype machine. TABLE I

PARAMETERS OF SFPM PROTOTYPE MACHINE

\begin{tabular}{ccc}
\hline \hline Quantity & Value & Unit \\
\hline Rated torque & 2.7 & $\mathrm{Nm}$ \\
Rated speed & 400 & $\mathrm{r} / \mathrm{min}$ \\
Stator pole number & 12 & \\
Rotor pole number & 10 & \\
$d$-axis inductance, $L_{d}$ & 0.277 & $\mathrm{mH}$ \\
$q$-axis inductance, $L_{q}$ & 0.339 & $\mathrm{mH}$ \\
\hline \hline
\end{tabular}

\section{A. Evaluation of Proposed Rotor Position Estimations} Based on the Sixth-Harmonic Back-EMF

The estimated rotor positions based on integration, zerocrossings detection, and proposed method, at a constant speed of 100r/min, are shown in Fig. 12. Meanwhile, the comparison of position-tracking behavior, at a constant speed of $100 \mathrm{r} / \mathrm{min}$, is shown in Fig. 13. It shows the proposed method exhibits lower position estimation error and better performance.

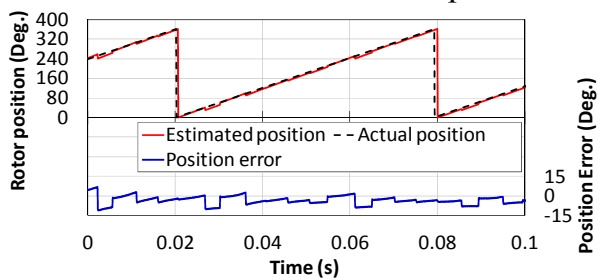

(a) Estimated position based on integration

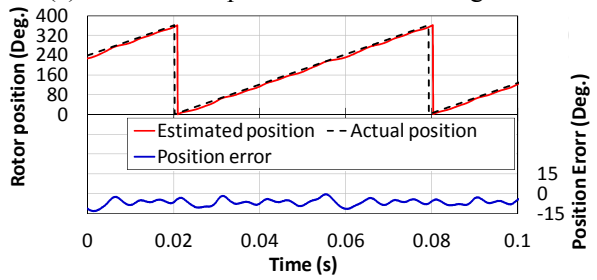

(b) Estimated position based on zero-crossings detection

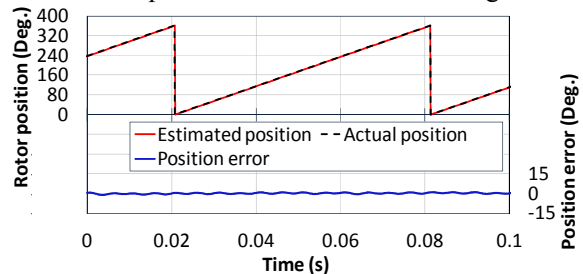

(c) Estimated position based on proposed method

Fig. 12. Rotor position estimation at steady state, $100 \mathrm{r} / \mathrm{min}$.

In Fig. 14, the dynamic performance of speed step-response from $50 \mathrm{r} / \mathrm{min}$ to $100 \mathrm{r} / \mathrm{min}$ is demonstrated. Figs. 14 (a) and (b) show that the rotor speeds calculated from the integration and zero-crossings detection have larger estimation errors during the speed step-change due to the unstable estimation of twelve accurate rotor positions. On the other hand, a good speed response by the proposed method is achieved as shown in Fig. 14 (c).

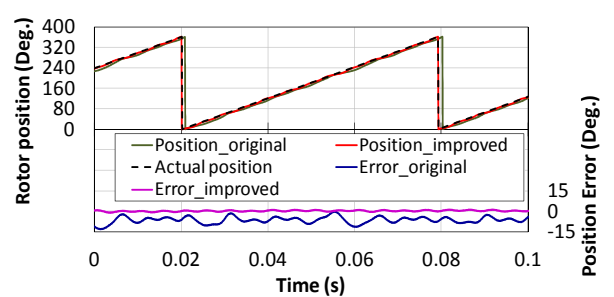

Fig. 13. Comparison of rotor position estimations, $100 \mathrm{r} / \mathrm{min}$.

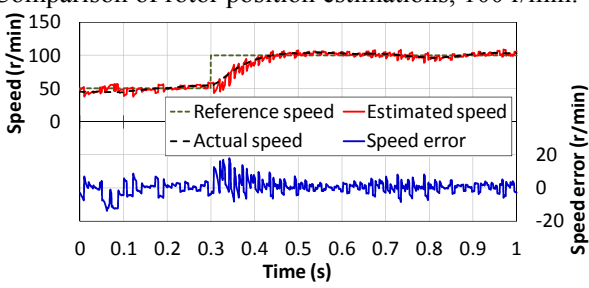

(a) Estimated speed based on integration

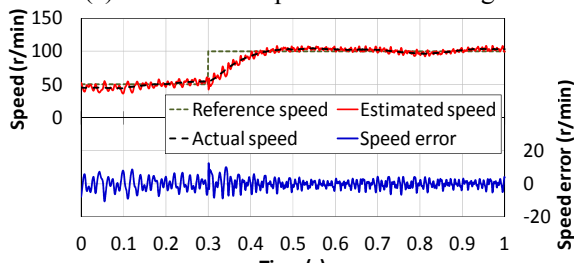

Time (s)

(b) Estimated speed based on zero-crossings detection

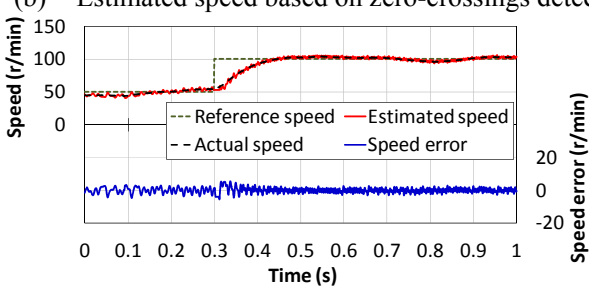

(c) Estimated speed based on proposed method

Fig. 14. Rotor speed estimation at dynamic-state, 50-100 r/min.

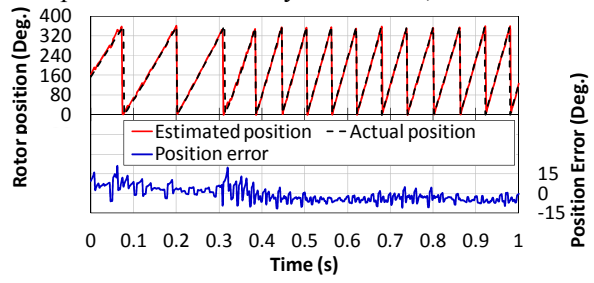

(a) Estimated position based on integration

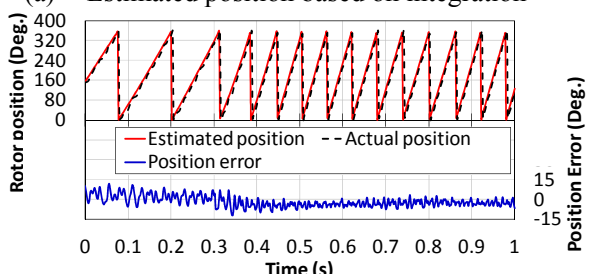

(b) Estimated position based on zero-crossings detection

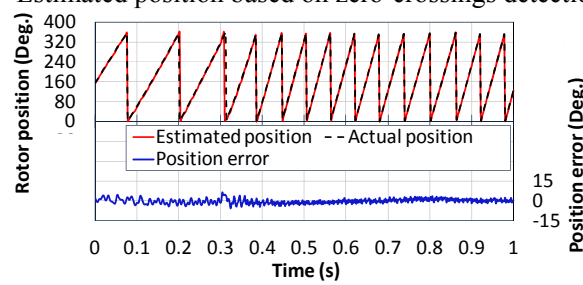

(c) Estimated position based on proposed method

Fig. 15. Rotor position estimation at dynamic-state, $50-100 \mathrm{r} / \mathrm{min}$. 
Similarly, the dynamic performances shown in Figs. 15 (a) and (b) have large errors due to sharp changes of estimated rotor position and inaccurate speed estimation. Fig. 15 (c) shows the estimated position error is significantly reduced by the proposed method. Although the estimated position error reaches up to $\pm 10 \mathrm{deg}$. during the transient process, the estimation error can still be limited to $\pm 5 \mathrm{deg}$. at steady state. Fig. 16 shows the performance from standstill to $100 \mathrm{r} / \mathrm{min}$. The sensorless control stage is switched in at $0.37 \mathrm{~s}$. During the speed increasing period, the estimated error is finally reduced and the estimated speed tracks well to the actual speed.

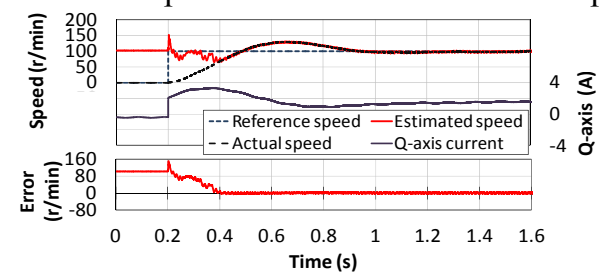

(a) Estimated speed and $q$-axis current response

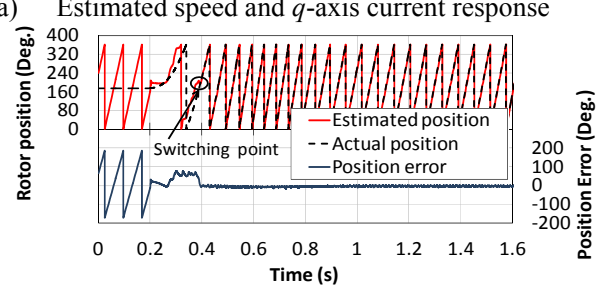

(b) Estimated position and error

Fig. 16. Speed-step responses, from zero to $100 \mathrm{r} / \mathrm{min}$, by proposed method.

\section{B. Rotor Position Estimations Based on Different Back- EMF Based Methods}

The comparison of rotor position estimations based on different back-EMFs based method is shown in Fig. 17. By analyzing the estimated position errors under the same testing condition, the estimation accuracies in the fundamental backEMF and the 3rd-harmonic back-EMF based methods have not performed as good as the proposed method due to influence of cross-coupling magnetic saturation [17].

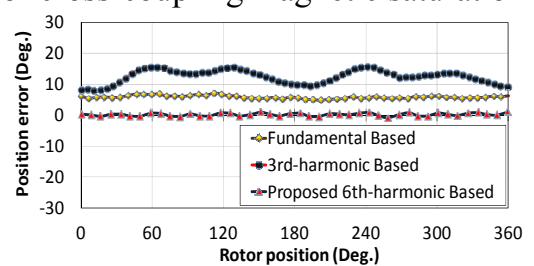

Fig. 17. Comparison of different back-EMF based methods, $100 \mathrm{r} / \mathrm{min}$.

\section{CONCLUSION}

This paper proposes the 6th-harmonic back-EMF based sensorless control strategy since its amplitude is bigger and dominant, whilst the 3rd-harmonic is relatively small which may easily fail in the rotor position estimation.

Considering the 3rd-harmonic and non-constant effects, the proposed observer together with the harmonic elimination and SRFF by utilizing the combined signals of the 6th-harmonic back-EMF and flux-linkage, the continuous rotor position is therefore obtained, and the high accuracy of rotor position estimation is achieved at different operating conditions.

Furthermore, comparing with the fundamental and the 3rdharmonic back-EMF based techniques, the proposed method has better performance due to less influence of cross-coupling magnetic saturation, but it still has limit in the low speed region as any flux linkages or back-EMF based methods.

\section{REFERENCES}

[1] T. Bernardes, V. Montagner, H. Grundling, and H. Pinheiro, "Discretetime sliding mode observer for sensorless vector control of permanent magnet synchronous machine," IEEE Trans. Ind. Electron., vol. 61, no. 4, pp. 1679-1691, Apr. 2014.

[2] F. G. Rosario, C. Rando, and G. R. Galluzzo, "Back EMF sensorlesscontrol algorithm for high-dynamic performance PMSM," IEEE Trans. Ind. Electron., vol. 57, no. 6, pp. 2092-2100, Jun. 2010.

[3] E. Al-nabi, B. Wu, N. R. Zargari, and V. Sood, "Sensorless control of CSC-fed IPM machine for zero- and low-speed operations using pulsating HFI method," IEEE Trans. Ind. Electron., vol. 60, no. 5, pp. 1711-1723, May 2013.

[4] D. Reigosa, F. Briz, C. Blanco, A. Di Gioia, P. Garcia, and J.M. Guerrero, "Sensorless control of doubly fed induction generators based on rotor high-frequency signal injection," IEEE Trans. Ind. Appl., vol. 49, no. 6, pp. 2593-2601, Nov.-Dec. 2013.

[5] T.C. Lin, L.M. Gong, J.M. Lin and Z.Q. Zhu "Investigation of saliency in switched-flux permanent magnet machine using high-frequency signal injection," IEEE Trans. Ind. Electron., no.99, pp.5094-5104, 2014.

[6] J.X. Shen, Z.Q. Zhu, and D, Howe, "Improved speed estimation in sensorless PM brushless AC drives," IEEE Trans. Ind. Appl., vol. 38, no. 4, pp. 1072-1080, 2002.

[7] G. Pellegrino, E. Armando, and P. Guglielmi, "Direct flux vector control of IPM motor drives in the maximum torque per voltage speed range," IEEE Trans. Ind. Electron., vol.59, no.10, pp.3780-3788, 2012.

[8] F.R. Salmasi, T.A. Najafabadi, P.J. Maralani, "An adaptive flux observer with online estimation of DC-link voltage and rotor resistance for VSI-based induction motors," IEEE Trans. Power Electron., vol. 25 ,no. 5, pp. $1310--1319,2010$,

[9] O. Vainio and S. J. Ovaska, "Noise reduction in zero crossing detection by predictive digital filtering," IEEE Trans. Ind. Electron., vol. 42, pp. 58--62, Feb. 1995.

[10] J.X. Shen, and S. Iwasaki, "Sensorless control of ultrahigh-speed PM brushless motor using PLL and third harmonic back EMF," IEEE Trans. Indus. Electron., vol. 53, no. 2, pp. 421 - 428, 2006.

[11] J.X. Shen, Z.Q. Zhu, and D. Howe, "Practical issues in sensorless control of PM brushless machines using third-harmonic back-EMF," IEEE 5th International Power Electronics and Motion Control Conference, IPEMC2006, 2006, pp. 1-5.

[12] L. Kreindler, J.C. Moreira, A. Testa, and T. A. Lipo, "Direct field orientation controller using the stator phase voltage third harmonic," IEEE Trans. Ind. Appl., vol. 30, no. 2, pp. 441-447, 1994.

[13] J. Moreira, and T.A. Lipo, "Modeling saturated AC machines including air gap flux harmonic components," IEEE Trans. Ind. Appl., vol. 28, no.2, pp. 343-349, 1992.

[14] J. Liu and Z. Zhu, "Improved sensorless control of permanent magnet synchronous machine based on third-harmonic back-EMF," IEEE Trans. Ind. Appl., vol.50, no.3, pp.1861-1870, May-June 2014.

[15] Z. Wang, K. Lu and F. Blaabjerg, "A simple startup strategy based on current regulation for back-EMF-based sensorless control of PMSM," IEEE Trans. Power Electron., vol.27, no.8, pp.3817-3825, Aug. 2012.

[16] T. Emura, L. Wang, M. Yamanaka, and H. Nakamura, "A high precision positioning servo controller based on phase/frequency detecting technique of two-phase-type PLL," IEEE Trans. Ind. Appl., vol. 47, no. 6, pp. 1298-1306, Nov./Dec. 2000.

[17] Z. Q. Zhu, Y. Li, D. Howe, C. M. Bingham, and D. Stone, "Influence of machine topology and cross-coupling magnetic saturation on rotor position estimation accuracy in extended back-EMF based sensorless PM brushless AC drives," in Proc. 42nd IAS Annu. Meet., 2007, pp. 2378-2385. 